\title{
V. Table and formulœ for reducing registers of the height of the barometer to the standard temperature and level
}

\section{Mr. J. Nixon}

To cite this article: Mr. J. Nixon (1827) V. Table and formulœ for reducing registers of the height of the barometer to the standard temperature and level, Philosophical Magazine Series 2, 1:1, 15-18, DOI: $10.1080 / 14786442708674197$

To link to this article: http://dx.doi.org/10.1080/14786442708674197

曲 Published online: 10 Jul 2009.

Submit your article to this journal $[\pi$

Џll Article views: 2

Q View related articles $₫$ 
Being partly aware of the transverse strength from the former experiment, the time used for applying the first part of the load was shortened; but towards the conclusion the additions were cautious and slow, and the whole time occupied in the experiment was $57 \frac{1}{4}$ minutes; the breaking weight was 506 pounds, which gives 59,950 pounds per square inch, for the cohesion, or in round numbers 60,000 pounds, and the mean of both 60,500 pounds. Yours truly, Leighton, Dec. 11, 1826.

B. Bevan.

P.S. I have lately seen in the public papers, under the title of Curious Weather-gauge, an account of a machine invented by $\mathrm{Mr}$. Donovan, capable of showing the commencement and termination of every shower, and the rate of raining, with the quantity fallen.

I beg leave to say, that I have several rain-gauges of such a nature as to exhibit all these particulars; one of which has been in constant use for fifteen years.-Further particulars I perhaps may give at another time.

V. Table and Formula for reducing Registers of the Height of the Barometer to the Standard Temperature and Level. By $M r$. J. Nixon.

\section{To the Editors of the Philosophical Magazine and Annals.}

Gentlemen,

NE of the many obstacles to the advancement of the degraded science of Meteorology, is confessedly the difficulty of an immediate comparison of the pressure of the atmosphere, as registered at places differing in elevation and temperature. So intolerably irksome to the man of genius, anxious to devote his talents to this obscure branch of philosophy, must be the unintellectual toil of rendering a vast number of similar registers comparable with each other, that the true lover of the science cannot but indulge in the wish, that the editors of scientific journals would invariably decline the insertion of meteorological registers unreduced to the standard level and temperature.

To render the task thus imposed on the observer as easy and brief as is compatible with the requisite accuracy, I have taken the liberty of transmitting you the annexed Table, derived from the following formulæ: in which $h$ denotes the observed height of the barometer corrected for the varying height of the surface of the mercury in the cistern, and for the effect of capillary attraction; T the height of the detached thermometer (or temperature of the mercury); $a$ the elevation 


\section{Mr. Nixon on reducing Barometrical Registers to the}

of the barometer in feet above the level of the sea; and $t$ the observed temperature of the air.

Formula No. 1.-Reduction of the pressure $h$ to its value at the standard temperature of $32^{\circ}$ Fahr. $=h '$.

$$
h^{\prime}=h \pm \frac{\overline{\mathrm{TON}} 3^{2} \times h}{11121+\mathrm{T}}
$$

additive or subtractive as $\mathrm{T}$ is below or above $32^{\circ} \mathrm{Fahr}$.

No. 2.-Reduction of the pressure at $32^{\circ} \mathrm{Fahr} .=h^{\prime}$ to its value at the level of the sea $=\mathrm{H}$.

$$
\log . H=\log . h^{\prime}+\frac{a}{56054 \cdot\left(1+\frac{t+\frac{a}{500}}{418}\right)}
$$

No. 3.-Reduction of the observed pressure $h$ to its value at the level of the sea, and standard temperature of $32^{\circ} \mathrm{Fahr} .=\mathrm{H}$.

$$
\log . \mathrm{H}=\log . h \pm \frac{69 \cdot 8\left(1+\frac{t+\frac{a}{500}}{418}\right)+a \text { a } 2 \cdot 2\left(1+\frac{t+\frac{a}{500}}{418}\right) \times \mathrm{T}}{56054 \cdot\left(1+\frac{t+\frac{a}{500}}{418}\right)} ;
$$

the upper or lower sign to be used as $69.8 \& \mathrm{c} .+a$ is greater or less than $2 \cdot 2 \& \mathrm{c}$. $\times \mathrm{T}^{*}$.

\section{Explanation of the Use of the Table.}

For formula No. 3.-1 $1^{\circ}$. To the observed temp. of the air add $\frac{1}{5} \frac{1}{0}$ part of the alt. which term the mean temp.

$2^{\circ}$. With the mean temp. enter the col. A, and take out the corresponding quantity in col. $\mathrm{B}$, which add to the altitude.

$3^{\circ}$. With the mean temperature for the first column take out the corresponding quantity in column $\mathrm{C}$, which multiply by the height of the detached thermometer.

$4{ }^{\circ}$. Note the difference of this produot and the sum last found, marking it positive or negative as the sum is greater or less than the product.

$5^{\circ}$. Multiply this difference by the quantity given in the column $\mathrm{D}$ corresponding to the mean temperature found in the first column, and divide the product by 1000 .

$6^{\circ}$. To the logarithm of the observed pressure, (corrected for capacity and capillarity,) add or subtract, according to the sign prefixed to the difference, the quotient just found, which

$$
\text { * Approximatively, } \quad \log . \mathrm{H}=\log . h \pm \frac{\overline{a+78} \backsim \overline{2^{\circ} 4 \times \mathrm{T}}}{56054 .\left(1+\frac{t+\frac{a}{500}}{418}\right)}
$$


will be the logarithm of the pressure required, at the standard temperature of $32^{\circ}$ Fahr.-Example:

$$
\begin{aligned}
& h=29.500 \text { inches; } \mathrm{T}=60^{\circ} ; t=59^{\circ} ; a=500 \text { feet. } \\
& \text { 5 } \frac{1}{0} \text { ) } 500+79 \cdot 9 \text { (See column B.) } \\
& +500 \cdot 0 \\
& +59 \quad \overline{579.9} \text { Sum } \\
& \text { mean temp. } \overline{60^{\circ}} \quad 2.5 \times 60=\underline{150^{\circ} 0} \text { Product } \\
& +\overline{429 \cdot 9} \text { Difference } \\
& \frac{\times \cdot 015601}{\frac{1}{100} \overline{6 \cdot 7069}} \text { (See column C.) } \\
& \text { log. of } 29 \cdot 500=1 \cdot 4698220 \\
& \text { log. of } 29.959=\overline{1.4765289}
\end{aligned}
$$

For formule Nos, 1 and 2.- If we prefer to reduce the observed pressure in the first instance to its value at $32^{\circ}$ Fahr. the process of calculation will be as follows :

$$
\text { By Formula No. 1. } \begin{aligned}
\frac{60-32 \times 29 \cdot 5}{1121+60}=\frac{826}{11181} & =-\begin{array}{r}
\cdot 0739 \\
h
\end{array}=\underline{29 \cdot 5000} \\
h^{\prime} & =\underline{29 \cdot 4261}
\end{aligned}
$$

Entering the first column of the table with the mean temperature, take the corresponding number in the last column, which multiply by the altitude. Divide the product by 1000 , and add the quotient to the logarithm of the pressure at $32^{\circ}$ Fahr.-Example :

015601

$$
\begin{aligned}
\frac{1}{1000} & \frac{\times 500}{7 \cdot 8005} \\
& +0.0078005 \\
\text { log. of } 29 \cdot 4261 & =1.4687327 \\
\text { log. of } 29.959 & =1.4765332
\end{aligned}
$$

The elevation of the barometer, when placed in the vicinity of the sea, may be readily ascertained by levelling, trigonometrically, or by the portable barometer. When the situation is inland, its height relative to the nearest canal, mountain, or other object of which the absolute elevation has been well determined, may be obtained by one or other of the methods above mentioned. As a last resource,-extract from the different scientific journals the annual mean pressures furnished by barometers placed at given elevations above the sea in the vicinity of the observer, which data, in addition to the annual mean height of his own instrument, will enable him to ascertain on calculation the required difference of level.

Leeds, Dec. 5, 1826.

I have the honour to be, \&c.

New Series. Vol, 1. No. 1. Jan. 1827.

D T. Nixon. 
Table.

\begin{tabular}{|c|c|c|c|c|c|c|c|}
\hline A & B & $\mathrm{C}$ & D & $\mathbf{A}$ & B & $\mathbf{C}$ & D \\
\hline F & $70 \cdot 3$ & $2 \cdot 2$ & 713 & $43^{\circ} \mathrm{F}$ & $77 \cdot 0$ & $2 \cdot 4$ & 016176 \\
\hline 1 & $70 \cdot 5$ & $2 \cdot 2$ & 71 & 44 & $77 \cdot 2$ & $2 \cdot 4$ & \\
\hline 5 & $70 \cdot 7$ & $2 \cdot 2$ & & 45 & $77 \cdot 4$ & $2 \cdot 4$ & \\
\hline 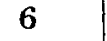 & $70 \cdot 8$ & $2 \cdot 2$ & & 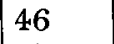 & $77 \cdot 5$ & $2 \cdot 4$ & $\cdot 016$ \\
\hline 7 & $71 \cdot 0 \mid$ & $2 \cdot 2$ & & 47. & $77 \cdot 7$ & $2 \cdot 4$ & \\
\hline 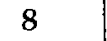 & $71 \cdot 2$ & $2 \cdot 2$ & & 48 & $77 \cdot 9$ & $2 \cdot 4$ & \\
\hline 9 & $71 \cdot 3$ & $2 \cdot 2$ & & 49 & $78 \cdot 0$ & $2 \cdot 4$ & \\
\hline 10 & $71 \cdot 5$ & $2 \cdot 2$ & & 50 & $78 \cdot 2$ & $2 \cdot 4$ & \\
\hline 1. & $71 \cdot 7$ & $2 \cdot 2$ & & 51 & $78 \cdot 4$ & $2 \cdot 4$ & \\
\hline & $71 \cdot 8$ & $2 \cdot 2$ & & 52 & $78 \cdot 5$ & $2 \cdot 5$ & \\
\hline & $72 \cdot 0$ & $2 \cdot 3$ & & 53 & $78 \cdot 7$ & $2 \cdot 5$ & \\
\hline & $72 \cdot 2$ & $2 \cdot 3$ & & 54 & $78 \cdot 9$ & $2 \cdot 5$ & \\
\hline & $72 \cdot 3$ & $2 \cdot 3$ & & 55 & $9 \cdot 0$ & $2 \cdot 5$ & \\
\hline & $72 \cdot 5$ & $2 \cdot 3$ & & 56 & $9 \cdot 2$ & $2 \cdot 5$ & \\
\hline 17 & $|72 \cdot 7|$ & $2 \cdot 3$ & & 57 & $79 \cdot 4$ & $2 \cdot 5$ & \\
\hline & $72 \cdot 8$ & $2 \cdot 3$ & & 58 & $9 \cdot 5$ & 2.5 & \\
\hline & $73 \cdot 0$ & $2 \cdot 3$ & & 59 & $79 \cdot 7$ & $2 \cdot 5$ & \\
\hline & $73 \cdot 2$ & $2 \cdot 3$ & $\cdot 0$ & 60 & $79 \cdot 9$ & $2 \cdot 5$ & \\
\hline & $|73 \cdot 4|$ & $2 \cdot 3 \mid$ & & 61 & 0.0 & $2 \cdot 5$ & \\
\hline & $73 \cdot 5$ & $2: 3$ & & 62 & $0 \cdot 2$ & $2 \cdot 5$ & \\
\hline & $|73 \cdot 7|$ & $2 \cdot 3$ & & 63 & $80 \cdot 4$ & $2 \cdot 5$ & \\
\hline 24 & $73 \cdot 9$ & $2 \cdot 3$ & .01 & 64 & $80 \cdot 5$ & $2 \cdot 5$ & \\
\hline & $74: 0$ & $2 \cdot 3$ & & 65 & $80 \cdot 7$ & $2 \cdot 5$ & \\
\hline 26 & $74 \cdot 2$ & $2 \cdot 3$ & & 66 & 80.9 & $2 \cdot 5$ & \\
\hline & $74 \cdot 4$ & $2 \cdot 3$ & & 67 & $81 \cdot 0$ & $2 \cdot 5$ & \\
\hline & $74 \cdot 5$ & $2 \cdot 3$ & & 68 & $81 \cdot 2$ & $2 \cdot 5$ & \\
\hline 25 & $|74 \cdot 7|$ & $2 \cdot 3$ & & 69 & $81 \cdot 4$ & $2 \cdot 5$ & \\
\hline & $74: 9 \mid$ & $2 \cdot 3$ & & 70 & 1.5 & $2 \cdot 5$ & \\
\hline 3 & $75^{\circ} 0$ & $2 \cdot 3$ & & 71 & $81 \cdot 7$ & $2 \cdot 6$ & \\
\hline 3 & $75 \cdot 2$ & $2 \cdot 3$ & & 72 & $81 \cdot 9$ & $2 \cdot 6$ & \\
\hline 39 & $75^{\circ} 4$ & $2 \cdot 4$ & & 73 & $82 \cdot 0$ & $2 \cdot 6$ & \\
\hline 34 & $75 \cdot 5$ & $2 \cdot 4$ & & 74 & $82 \cdot 2$ & $2 \cdot 6$ & \\
\hline & $75 \cdot 7 \mid$ & $2 \cdot 4$ & & 75 & $82 \cdot 4$ & $2 \cdot 6$ & \\
\hline 36 & $75 \cdot 9$ & $2 \cdot 4$ & & 76 & $82 \cdot 5$ & $2 \cdot 6$ & \\
\hline 37 & $76 \cdot 0$ & $|2 \cdot 4|$ & & 77 & $82 \cdot 7$ & $2 \cdot 6$ & \\
\hline 38 & $76 \cdot 2$ & $2 \cdot 4$ & & 78 & 82.9 & $2 \cdot 6$ & \\
\hline 3 & 76 & $2 \cdot 4$ & & 79 & $83 \cdot 0$ & $2 \cdot 6$ & \\
\hline 40 & $76 \cdot 5$ & $2 \cdot 4$ & 282 & 80 & $83 \cdot 2$ & $2 \cdot 6$ & $\cdot 014974$ \\
\hline 41 & $76^{\circ} 7$ & $2 \cdot 4$ & & 81 & 83.4 & $2 \cdot 6$ & 4944 \\
\hline 42 & 9 & $2 \cdot 4$ & $\cdot 016211$ & 82 & $83 \cdot 5$ & $2 \cdot 6$ & .014915 \\
\hline
\end{tabular}

VI. Further 